\title{
Thoughts on Humanistic Care of High-tech Enterprises in the Era of Big Data
}

\author{
Xufeng $\mathrm{Li}^{1}$, a Meijie $\mathrm{Ji}^{2} \quad$ Lingling $\mathrm{Su}^{3}$ \\ ${ }^{1}$ Department of Management, Northwest Minzu University, Lanzhou, China \\ ${ }^{2}$ Department of Management, Northwest Minzu University, Lanzhou, China \\ ${ }^{3}$ Department of Management, Northwest Minzu University, Lanzhou, China \\ ${ }^{4}$ Department of Management, Northwest Minzu University, Lanzhou, China \\ ${ }^{a}$ Corresponding author. Email: $1250017862 @ q q . c o m$
}

Yanhua $\mathrm{Liu}^{4}$

\begin{abstract}
The era of big data has come. As high-tech enterprises continue to deepen the application of big data, some problems have also appeared. Enterprises lack humanistic care for employees. Therefore, this article takes the era of big data as the background, and puts forward relevant thoughts on the humanistic care of high-tech enterprises. High-tech enterprises lack of humanistic care due to the nature of the company, the single incentive method, the heavier utilitarianism, and the overly strict rules and regulations. This article proposes to use big data to improve the adverse effects of the nature of high-tech enterprises, optimize the corporate incentive mechanism, so that incentives can mobilize the enthusiasm of employees, strengthen the care for employees , attach importance to the people-oriented concept and pay attention to the interests of employees, promote employee assistance programs, and realize humanized management and other related countermeasures.
\end{abstract}

Keywords: Big Data Era; High-tech enterprises; Humanistic care; Knowledge employees

\section{INTRODUCTION}

With the continuous integration and development of the real economy and the digital economy, "big data" has gradually become the focus of individuals, enterprises and even the country. The era of big data has arrived, and "big data" is changing and affecting our way of life and thinking mode. Professor Han Han pointed out in the article "On "Big Data" and the Turn of Humanities Research", Big data", as the future human social organization form, will lead to the characteristics of "dataization" in human society [1]. High-tech enterprises pay attention to and emphasize the application and practice of big data to improve the efficiency of enterprises, However, in this process, high-tech enterprises pay too much attention to organizational value, but ignore the humanistic care for employees. President Xi Jinping once emphasized the use of big data to promote the protection and improvement of people's livelihood, enhancing humanistic care is an important foundation for enterprises to achieve strategic goals. This article aims to make high-tech enterprises pay more attention to the needs of employees in the era of big data, and call for humanistic care while using big data.

\section{RELATED CONCEPTS AND THEORETICAL BASIS}

\subsection{Big Data}

It refers to the huge amounts of data rapidly changing, it requires a new processing model to have more decisionmaking power, Insight discovery and process optimization capabilities to adapt to massive, high growth rates and diversified information assets.

\subsection{Humanistic care}

The term humanistic care was first proposed by Alan Bullock in the book "Western Humanistic Tradition". He affirms human nature, respects human value, require individual liberation, pursue freedom and equality, and care about people's spiritual life. Specifically, respect for the person's dominant position.

\subsection{Knowledge employees}

This was put forward by the American scholar Peter Drucker, refers to "those who master and use symbols and 
concepts, and work with knowledge or information. knowledge employees have a higher level of cultural quality, compared with ordinary employees, knowledge employees not only have a wider range of knowledge, but also have a relatively higher level of professional knowledge, which can create more value for the enterprise.

\subsection{Efficiency management theory}

This theory refers to safeguarding the interests of capital, taking efficiency as a work goal, and maximizing the interests of employers. The maximization of the employer's interests is achieved by the maximum enthusiasm of the workers. The theory of efficiency management requires people to obey the system and the way of working by machines, and strictly manage employees.

\subsection{Employee Assistance Program (EAP)}

Employee Assistance Program refers to the use of scientific methods by enterprises to actively pass planning, publicity, research, counselling, evaluation, and other services so that solve employees' social, psychological, management and health problems. Improve employees' work performance and quality of life.

\section{PREPARE ON THE PROBLEMS OF HUMANISTIC CARE IN HIGH-TECH ENTERPRISES IN THE ERA OF BIG DATA}

\subsection{Issues of humanistic care for enterprises caused by the nature of high-tech enterprises.}

In the era of big data, high-tech enterprises cannot avoid paying more attention to the use of the Internet and data. Most employees focus on computers and data all day, and they don't have time to communicate feelings. During working hours, there is a lack of communication and exchanges between colleagues, just focusing on the computer to handle their busy business. At the end of get off work, because of a complicated and tedious day of mental work, they didn't have the energy to improve the relationship with their family. Due to cumbersome work and lack of support from family members, employees of high-tech enterprises are often under greater pressure, which has a negative impact on their mental health. However, the company did not pay attention to the mental health of employees and did not realize the necessity of psychological counselling.

Working at full load every day, sitting at a desk for a long time, a relatively small and closed working environment, and a tense and depressing working atmosphere have also caused great damage to the physical health of employees. Employees use computers for a long time, which puts a great burden on the eyes, and radiation also has a bad effect on people. Occupational diseases seriously affect the healthy life of employees, Such as waist muscle strain, cervical spondylosis, bone hyperplasia, etc. They have brought great troubles to employees.

However, high-tech enterprises do not pay attention to this and lack care for their employees. Employees seem to be machines that constantly work. There is a lack of communication and exchanges between employees and colleagues, employees, and their families. This makes the relationship between them even more indifferent, and employees cannot feel the care and warmth brought by the company.

\subsection{The incentive form of high-tech enterprises is relatively single, which cannot form long- term incentive effects for employees.}

In the era of big data, technology and innovation of high-tech enterprises continue to develop However, its incentive method has not changed significantly. Since most employees of high-tech enterprises are knowledge workers, the number and quality of knowledge workers determine the competitiveness of high-tech enterprises. The incentive method used by high-tech enterprises is traditional salary incentives, which can no longer provide good incentives for knowledge employees. Remuneration-related incentives are fundamental to knowledge workers, but their effects are relatively ineffective in stimulating knowledge workers' enthusiasm for work. Lack of long-term results, cannot make employees feel satisfied. The motivation for knowledge employees cannot be simple salary incentives. Knowledge employees have already met the lower-level needs, and they pursue higher-level needs, so only using salary incentives cannot achieve the incentive effect.

\subsection{High-tech enterprises emphasize utilitarianism and ignore the individual needs of employees.}

In the context of the era of big data, the speed of technology and product update and iteration of high-tech enterprises is very rapid. This has also led to increasingly fierce competition among high-tech enterprises and increasing demands on employees. High-tech enterprises comply with efficiency management theory, Utilitarian purpose is heavier, only focusing on the outcome of the event and the overall interests of the enterprise. [2] In this process, the interests of employees and their individual needs are ignored. "You have to consider the overall situation" has become the mantra of leaders to prevaricate employees. High-tech enterprises are accustomed to talking abstractly about the overall interests of the company, ignoring that everyone promotes the overall 
development. For employees working in high-tech enterprises, it will make them feel negative. They cannot have a sense of belonging to the company and cannot mobilize the enthusiasm of work. High-tech enterprises pay more attention to utilitarianism, and emphasize the use of employees rather than development and training. Regarding the lack of talents, most of them also choose to recruit directly from the outside to quickly obtain the talents needed by the enterprise, rather than internally cultivated and allocated. This not only discourages the enthusiasm of employees within the company, but also hinders the cultivation of talents.

\subsection{High-tech companies have too strict management systems and lack humanistic care for employees}

Compared with other enterprises, high-tech enterprises pay more attention to rational data, and Use data-based standards to measure whether employees comply with the system and their contributions to the company. For example, strict regulations on commuting time and Clock in and out. Distribute performance rewards based on specific and quantifiable standards. Distribute performance rewards based on specific and quantifiable standards. Too mechanical and cold, lacking human temperature. High-tech enterprises have serious administrative management behaviors, turning management goals into things, but failing to transform the implementation of rules and regulations into employees' spontaneous behavior, which will cause employees' confusion and disgust, and trigger a series of management problems. For employees, this makes it difficult for employees to establish a sense of responsibility and belonging to the company. For enterprises, the use of strict management systems to manage, reward and punish employees, use data-based rules and regulations to restrain employees is too rigid and is not conducive to the company's talent training and long-term development. For employees, acting in accordance with the rules and regulations, regardless of their personal circumstances, makes it difficult for employees to establish a sense of responsibility and belonging to the company.

In the era of big data, due to the strict management system of high-tech enterprises, it is more to strengthen than to guide employees. When companies need to complete specific tasks, they generally put more pressure on employees and require employees to complete them within the specified time, but they choose to avoid or delay the practical issues that employees care about. This management method will make employees feel oppressed, will cause employees to be dissatisfied with the company, and is not conducive to the long-term development of the company.

\section{THOUGHTS ON HUMANISTIC CARE OF HIGH-TECH ENTERPRISES IN THE BIG DATA ERA.}

\subsection{Learn to use big data to improve the adverse effects of the nature of high-tech enterprises.}

High-tech enterprises can use big data to understand the personalities and preferences of their employees, and organize more activities to strengthen the understanding and communication between employees. For example, holding team building activities, fun sports meet, charity activities, etc., Let employees contact and communicate with each other, strengthen their physique, and increase their sense of belonging and recognition of the company.

Regarding physical health, big data can also be used to derive the diseases that employees of high-tech companies are prone to, so as to prevent and treat them. For example, enterprises can use this as a basis to provide employees with physical examinations and medical insurance to reduce their physical burden. Purchase medical insurance for employees, so that employees can get better treatment when they are sick, and reduce employees' worries. In terms of psychology, enterprises can use big data to get the specific psychological conditions of employees and provide them with targeted psychological counseling and treatment. Enterprises should actively understand the psychological status of employees and grasp the psychological dynamics of employees. Regularly conduct psychological tests on employees, analyze their psychological conditions, sort out and integrate their psychological needs, and propose targeted improvement measures, In this way, the psychological pressure of employees is relieved, the psychological problems of employees are solved, and the negative emotions of employees are adjusted, so that employees can better mobilize enthusiasm at work, thereby improving work efficiency.

\subsection{Optimize the corporate incentive mechanism, so that incentives can mobilize the enthusiasm of employees.}

Optimize the corporate incentive mechanism, let the incentive mechanism reflect the personal value of employees, and realize humanistic care [3]. Firstly, Change the current situation of single incentive methods and focus on the combination of multiple incentive methods. Strengthen the spiritual rewards for knowledgebased employees. That is, the higher-level needs of employees are met. For example, respect the work of employees, affirm their work results, and provide employees with a certain amount of space and power to allow employees to develop their talents. Secondly, companies must grasp the characteristics of employees, that is, understand their psychological demands, and 
realize their psychological demands as much as possible, in this way, knowledge workers can be better motivated. Thirdly, Enterprise management must have a long-term vision and should pay attention to long-term incentive effects. Don't just focus on short-term benefits and ignore long-term benefits, and carry out effective and long-term employee incentive management.

\subsection{Strengthen the care for employees, attach importance to the people-oriented concept and pay attention to the interests of employees.}

High-tech enterprises should not overly follow the efficiency management theory, and should strengthen the people-oriented concept while pursuing interests. While pursuing overall interests, we must also pay attention to the personal interests of employees, and provide each employee with a platform to demonstrate their abilities. Create a good working environment for employees so that they can work in a clean and tidy environment. Give employees greater tolerance and understanding, so that employees can complete their work more passionately [4]. Enterprises must fully trust, respect, and care for employees, and avoid letting employees work without trusting them, and not dare to delegate power, which will cause employees to lose their work enthusiasm and sense of responsibility. Pay attention to the training and development of internal employees, establish a complete channel for employee promotion, and give employees sufficient space for development, which is also more conducive to the long-term development of the company. In short, a modern high-tech enterprise should be more people-oriented, employee-centered, and pay attention to humanistic care. Meet the needs of each employee for growth and self-development.

\subsection{Promote employee assistance programs and realize humanized management.}

Enterprises should promote the implementation of employee assistance programs, improve employees' sense of safety and comfort in the company. Enterprises should solve the employees' most important and direct interests, reduce their worries, and enable them to work better. To listen to the voices of employees, understand their needs, so as to better help employees.

Enterprises can implement humanized management through employee assistance programs and reflect their humanistic care for employees [5]. In terms of the most basic attendance, use big data to achieve flexible work. Flexible arrangement of employees' working hours, Stagger the working hours of employees according to the peak and low peak periods of working hours giving employees more freedom. In addition, big data can also be used to develop training plans for each employee. Help employees improve their corresponding abilities in a targeted manner, so that they can complete their work more easily and make their work more efficient. etc. A series of measures can achieve humanized management.

\section{CONCLUSION}

To sum up, in the era of big data, there have been new forms and changes in the humanistic care of high-tech enterprises. If high-tech enterprises want to stimulate their employees' work enthusiasm and improve their work efficiency, they must adhere to the people-oriented concept and strengthen their humanistic care. This article puts forward relevant thinking on the humanistic care of high-tech enterprises, but there are still deficiencies and defects. There are other problems in the humanistic care of high-tech enterprises that are worth investigating. The content related to corporate humanistic care in the era of big data is a topic worthy of discussion and research. This is a cutting-edge and innovative topic in line with the background of the times.

\section{REFERENCES}

[1] Han H, (2014) A Discussion of "Bigdata" and the Diversion of Humanistic Studies, Academic Journal of Jinyang, (03):22-25.

[2] Dong B, ( 2016 ) "On the Humanistic Care of Enterprises from the Perspective of Human Resource Management", Chinese \& Foreign Entrepreneurs,(01):165-166.

[3] Wu B and Li F, (2013) “An Empirical Study on the Motivation Methods of Knowledge Workers and Organizational Innovation Performance: Taking Zhongguancun High-tech Enterprises as an Example", Lanzhou Academic Journal,(06):105114.

[4] [4] Zhang J and Li J, (2011) “On the Humanistic Care of Chinese Modern Enterprise Management-Based on the Thinking of Foxconn's "Jumping" Event, Productivity Research, (09):6-7+35.

[5] Liu Y, (2021) "Analysis on the Causes of Enterprise Staff Drain Based on Staff Satisfaction" China Management Informationization, (03):148-149. 